\title{
ECONOMIC DESIGN OF RCC BOX CULVERT THROUGH COMPARATIVE STUDY OF CONVENTIONAL AND FINITE ELEMENT METHOD
}

\author{
Saurav $^{[1]}$, Ishaan Pandey ${ }^{[2]}$ \\ ${ }^{[1]}$ Assistant Professor, Department of Civil Engineering, \\ Jaypee University of Information Technology, Solan, Himachal Pradesh, India \\ ${ }^{[2]} \mathrm{M}$. Tech, Department of Civil Engineering, \\ Jaypee University of Information Technology, Solan, Himachal Pradesh, India \\ ${ }^{[1]}$ ersauravsupstar@rediffmail.com \\ ${ }^{[2]}$ ishan123pandey@gmail.com
}

Abstract: There are several researches already have been done on behavior of reinforced concrete (RC) box culverts in past with different conditions of loads. The design and analysis of box culverts is a complex task. The present era offers the finite element analysis of 3D model of structures, making it easier through software. The conventional methods have been used extensively for design but the use of finite element method (FEM) has not been so popular yet. Finite element analysis of box culvert for parametric studies has been carried out, even for different aspect ratio. Here an effort has been made to show the economic and effective design can be achieved by doing finite element analysis of a box culvert whose concept can be used for large structural design as well. This paper shows the comparative study of analysis of conventional method using STAAD software and of FEM using ANSYS software.

Keywords: Box Culvert, Finite Element Analysis, Software Comparison, ANSYS

\section{INTRODUCTION}

A box culvert is a structure consisting two parallel slabs monolithically connected to its vertical slabs allowing an opening for waterways and other ways. The box culverts are ideally suited for the low stream water bodies, railways crossing of high embankments, for road crossing of low or medium traffic density and for the sites where bearing capacity of soil is low. The overall dimension of a box culvert is kept within $4 \mathrm{~m} \times 4 \mathrm{~m}$ due to the fact of synergy deflection [4]. If only one box is implied for the purpose, it is called 'single celled box culvert' and if the purpose requires culvert of more than one box, it is called 'multi-celled box culvert'. A box culvert has many design and installation advantages. One such is that it does not need a separate foundation to be laid on. The bottom slab serves as a raft foundation hence minimizing the pressure on soil. The culvert experiences an up-thrust force from soil which has also been considered in the paper.

There are several types of loads acting on a box culvert such as self weight of the culvert, live load on top slab in the form of moving wheel load, earth pressure acting from outside, water and air pressure acting from inside and upward soil thrust on the bottom slab. Hence critical analysis of culvert is necessary to ensure the best service.

Box culvert while designing should also follow certain aspect ratio as it is important to obtain an optimum thickness of the slab. Kalyanshetti M. G and Gosavi S [5] have shown in their research that for a certain lengths of the culvert, there are different aspect ratios for obtaining economical design of box culvert.

Dynamic effect of moving truck has also been discussed by Chen S. S and Harik I. E in which a time dependent variable dynamic system is solved step by step. Calculations have been made considering parameters like truck velocity, surface roughness, damping ratio, truck culvert frequency ratio and road material. [8] The results found in the paper are uneconomic. Hence this paper can also find the way to make the design of dynamic effects on culvert more economic.

Kumar Y. V. and Dr Srinivas C [2] has done a computational analysis in STAAD and SAP2000 of box culvert and compared the results of the two software where the reinforcement, bending moment and shear stress is reduced than in Grillage analysis. But this paper shows more economic design through ANSYS.

The numerical results from the manual method and STAAD software has been compared by Lande A. C., Kamane S. K and Madhik S.A [3] to suggest critical load case. The various combinations of loads according to IRC and codes have been taken into account. The angle of repose of soil taken as $30^{\circ}$ gives the critical load on the culvert. 
The chosen fixed dimension of box culvert is firstly analyzed in STAADPro software that follows the conventional method to analyze the structure. The same culvert is analyzed in ANSYS 14.0 to get the results for finite element method with the same load conditions.

Foremost objective of the paper is to compare the results of analysis through conventional methods by STAAD software with FEM done by ANSYS software for developing economic design with same safety.

\section{REQUIREMENT OF FINITE ELEMENT METHOD}

The FEM is a numerical technique that has been used for various design and analysis purposes not only by the means of computer aided software but also manually. The complex systems dealing with real life problems, dynamic loads, impact loads, time and space dependent loads and the combinations of these can be dealt using this technique. The FEM provides detailed calculations of each part of the member under consideration for the critical system subjected to fixed or random loading.

This method can be employed using different software in present world such as SAP, ANSYS, ABAQUS FEA etc. The design and calculation of results due to complex loading have been made easier through the software. One such software is used in this paper to apply the FEM for the best results.

\section{LOADS ON THE CULVERT}

There are various types of loads acting on culvert during its service period. These loads may or may not remain constant as the time passes. While calculating the load on culverts, there are several factors to be kept in mind such as design parameters involving angle of dispersion of live load, coefficient of earth pressure, depth of cushion etc for critical loads. [5, 6]. Single type of load considered at a time will sometimes give worst case. But it is required to take the critical combination of all the loads acting on a structure. Any structure subjected to multiple types of loads must be analyzed as per the critical combination of the loads [3].

A box culvert during service period is subjected to the following loads:

$\checkmark$ Live Loads

$\checkmark$ Impact loads

$\checkmark$ Dead load of top and side slabs

$\checkmark$ Water pressure from inside

$\checkmark$ Earth pressure from outside

$\checkmark$ Earth's up-thrust

A critical combination of the above mentioned loads that has been considered in the analysis is -

- When the culvert is full that is when the water inside the culvert is to the height of internal side slab till the bottom of the haunch $[3,14]$

The random set of loads are considered as per the range specified [3]:

Live Load $=4 \mathrm{kN} / \mathrm{m}$

Dead load of top slab $=9.5 \mathrm{kN} / \mathrm{m}$

Side Slab weight $=27 \mathrm{kN}$

Water Pressure (linearly varying load) $=3.5 \mathrm{kN} / \mathrm{m}$ to $36.5 \mathrm{kN} / \mathrm{m}$

Earth Pressure (linearly varying load) $=3 \mathrm{kN} / \mathrm{m}$ to $24.6 \mathrm{kN} / \mathrm{m}$

Up-thrust from soil under bottom slab $=30 \mathrm{kN} / \mathrm{m}$

The modeling is done according to the properties of M20 grade concrete with the following properties.

Modulus of elasticity $=22360 \mathrm{~N} / \mathrm{mm}^{2}$

Poisson's ratio $=0.17$

Figure 1 shows the line diagrams of the loads that have been applied on the culvert in STAAD software. The two ends of the bottom slab are fixed so that the up-thrust can also be taken into consideration. Water pressure is linearly varying inside and earth pressure linearly varying outside the culvert. Live loads and dead loads are taken uniformly distributed load. A load case consisting of the critical combination of the applied loads has been taken into consideration. 


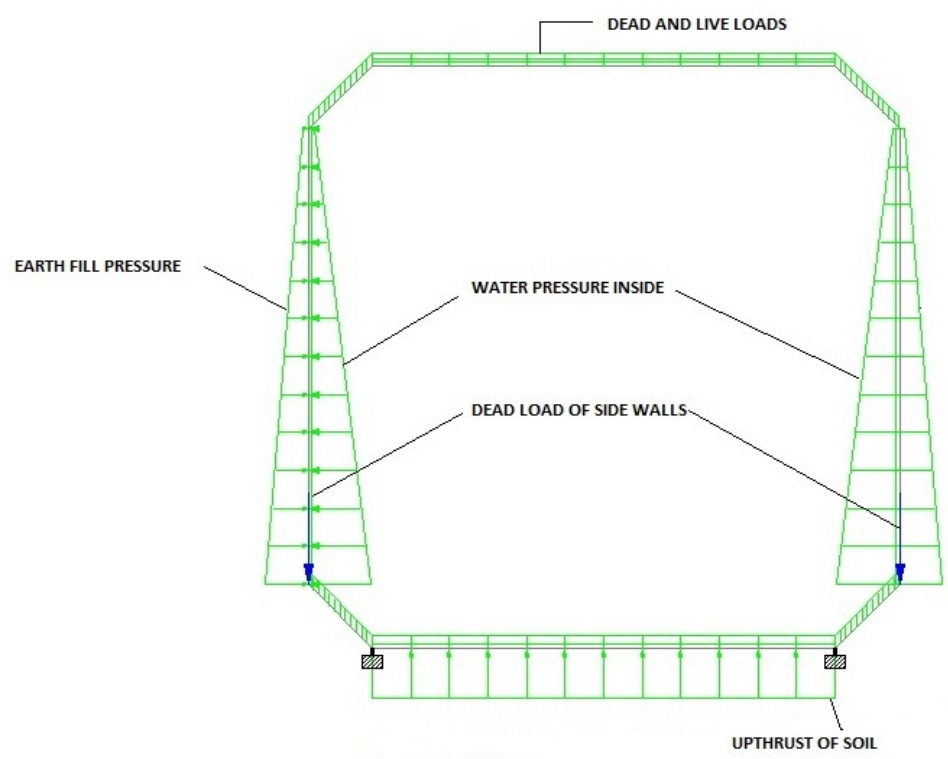

Fig. 1 Loads on the culvert in STAAD

\section{STAAD ANALYSIS AND RESULTS}

Fig. 2 shows the fixed ends reactions of the culvert in STAAD software. Reaction in X- direction, Y-direction and moment in Z-direction are found to be $25.005 \mathrm{kN}, 25.907 \mathrm{kN}$ and $70.882 \mathrm{kN}$-m respectively. Since the support reactions do not depend upon the method of analysis, the values remain same in both the software. The end reactions do not affect the economy of the structure and design criteria to be taken for the analysis.

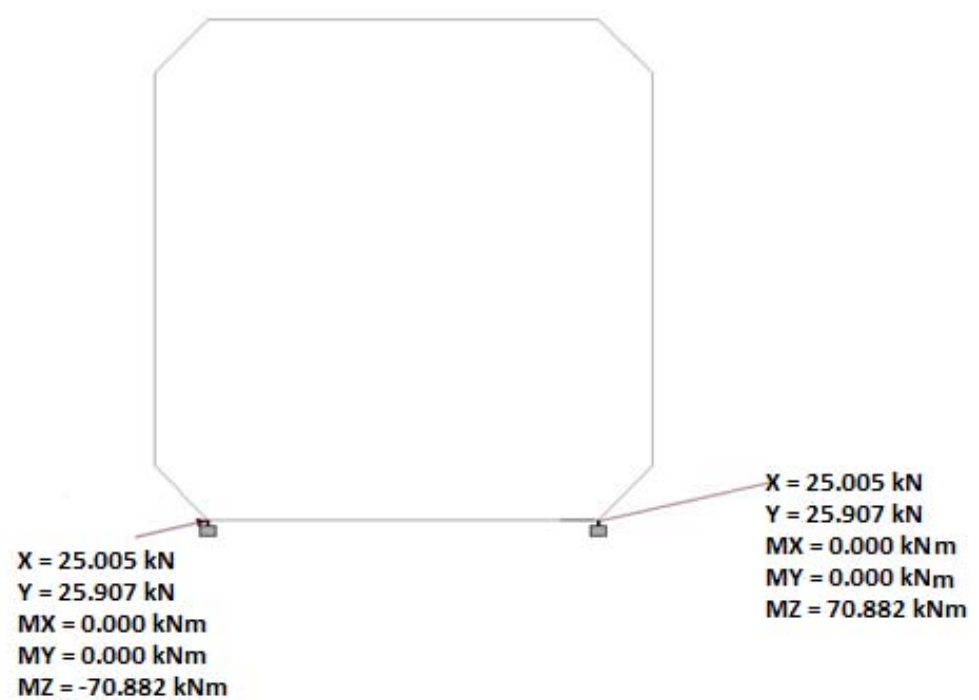

Fig. 2 Maximum value of the fixed ends reactions.

Fig. 3 shows the bending moment diagram in generated in STAAD software. The bending moment is the maximum in the top slab of the culvert. The edges of the haunches experience both negative and positive bending moment. The design of any structure is done according to the maximum bending moment in the monolithic structure. 


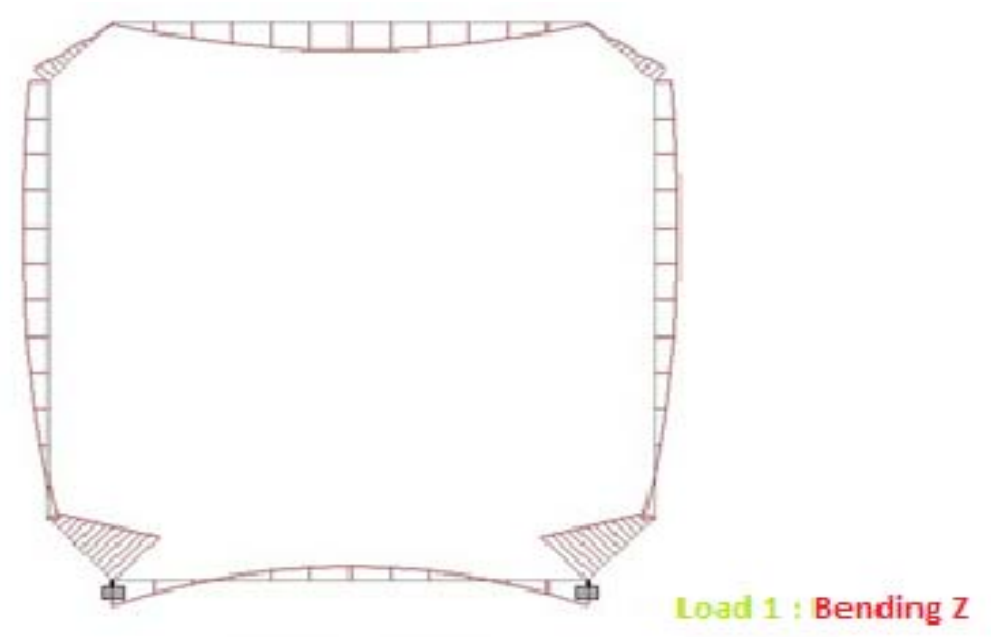

Fig. 3 Bending Moments in Beams and Haunches

\section{FINITE ELEMENT ANALYSIS IN ANSYS}

In the modern era, the FEM analysis can be performed to a large extent and with higher accuracy. There are several software available that can minimize the risk and give accurate results. Abolmaali A. and Garg A. k. [12] have also developed finite element models and performed experimental analysis designed as per ASTM C1433-05 to show the shear transfer device is unsupported across the joint. Software like SAP and ABAQUS have already been implemented for the analysis of box culvert for wheel load and other complex real life loads. It has been seen that the solution to such loads are not easy and sometimes impossible by the means of conventional methods $[11,13]$. FEM can be applied where the loads are dynamic in nature or where the varying loads are experienced [8]. The ANSYS software can make its mark in the field of analysis and design with accurate results and least effort and can solve these complex loads and simulate it to get critical case and effective and economic design.

Fig 4 shows the dimension of the culvert used in ANSYS which is same as in STAAD.

$4 \mathrm{~m} \times 4 \mathrm{~m}$ internally and with the wall thickness of $0.3 \mathrm{~m}$, its outer dimension is $4.6 \mathrm{~m}$. The 3-D model is in isometric view. The first step in the software is to correctly model the structure, then to apply the loads in the right directions so that accurate results can be obtained.

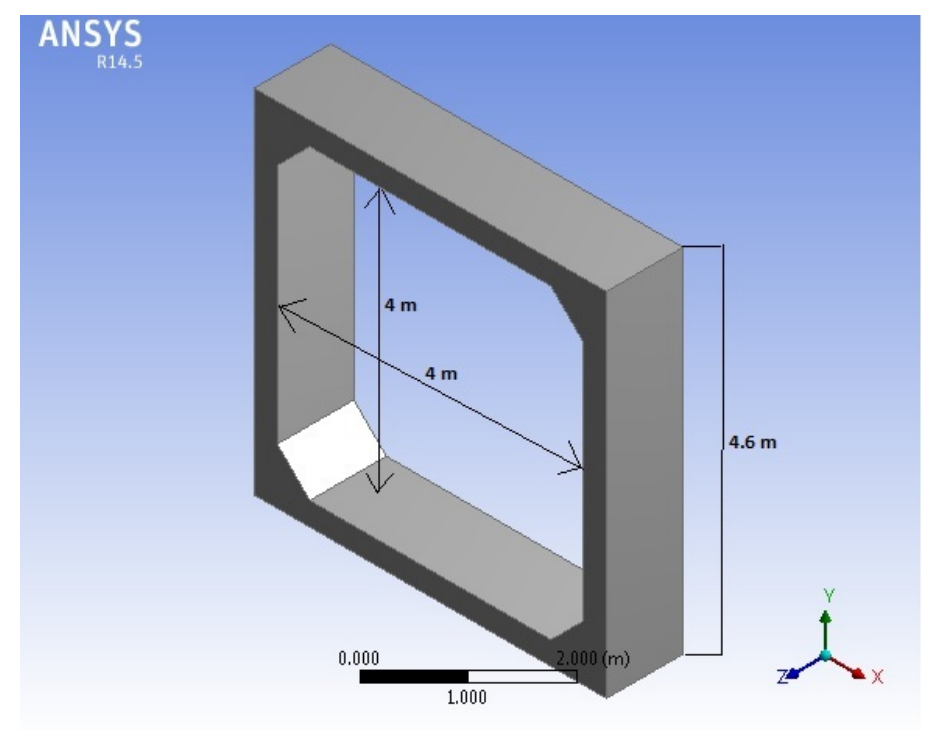

Fig. 4 Model of the Culvert in ANSYS

Fig. 5 shows the meshing of the box culvert into an integral structure. The most important part in the analysis of a structure by finite element method is breaking the overall the structure into different small elements before analyzing. The element taken here is solid65 which is capable of cracking in tension and crushing in compression. The solid65 element is generally used for 3D modeling of solid without reinforcement bars which is the case in this paper. They are also capable of plastic deformation and creep. 


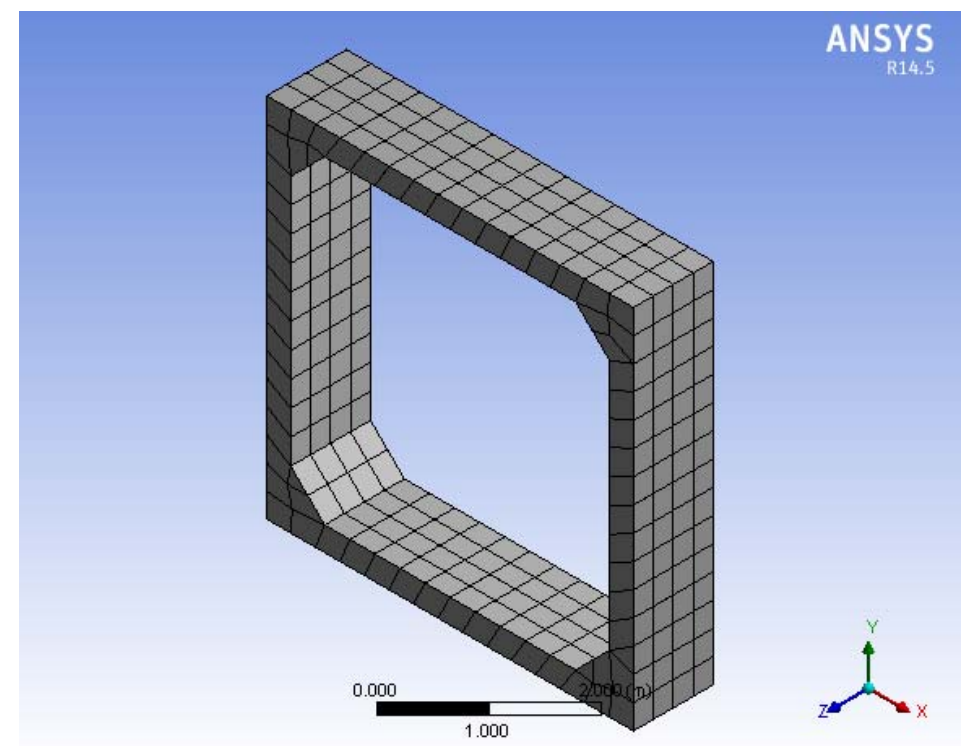

Fig. 5 Meshing Of Culvert

Fig. 6 shows the critical case loading on the culvert. All the loads acting together on the culvert is taken as per the critical case. The corresponding intensities of each load is shown on the left hand side inside the figure. The 3D model is loaded according to the loads in section 3 of the paper distributed per meter width.

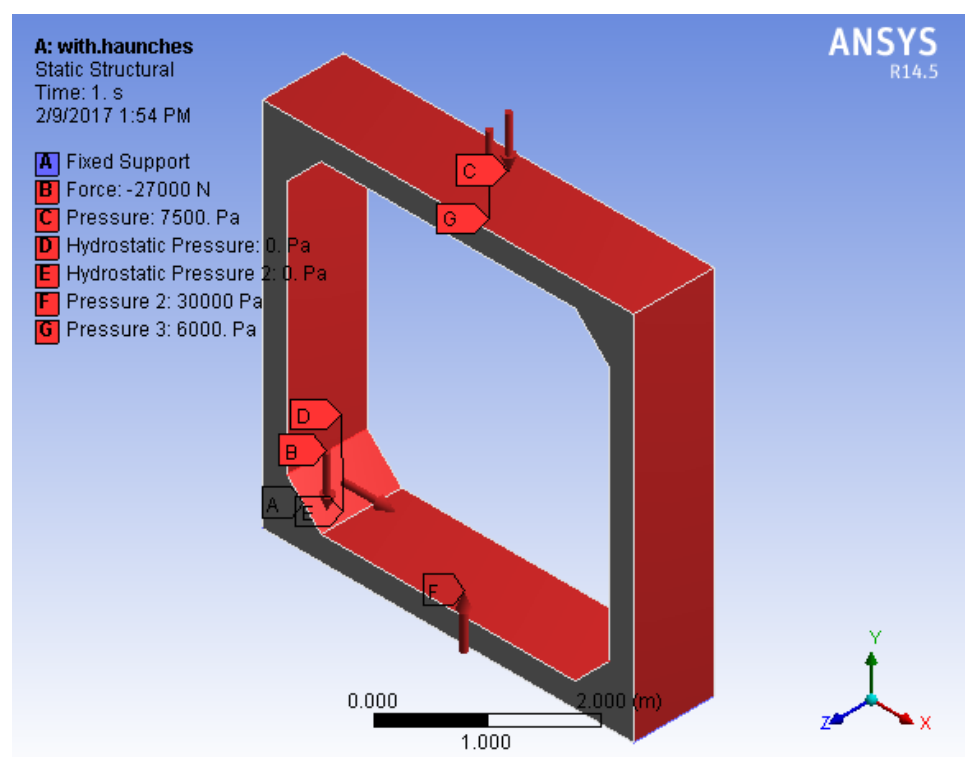

Fig 6 Loading On the Culvert in ANSYS 


\section{EVALUATION OF RESULTS FROM SOFTWARE}

TABLE I. Comparison of the two Methods

\begin{tabular}{|l|l|l|l|}
\hline Parameters & STAAD Analysis & ANSYS Analysis & Difference \\
\hline $\begin{array}{l}\text { Max Positive Bending } \\
\text { Moment }\end{array}$ & $49.282 \mathrm{kN}-\mathrm{m}$ & $41.168 \mathrm{kN}-\mathrm{m}$ & $16.46 \%$ \\
\hline $\begin{array}{l}\text { Max Negative Bending } \\
\text { Moment }\end{array}$ & $24.325 \mathrm{kN}-\mathrm{m}$ & $17.664 \mathrm{kN}-\mathrm{m}$ & $27.4 \%$ \\
\hline $\begin{array}{l}\text { Area of reinforcement } \\
\text { (positive B.M) }\end{array}$ & $5994 \mathrm{~mm}^{2}$ & $5479 \mathrm{~mm}^{2}$ & $8.6 \%$ \\
\hline $\begin{array}{l}\text { Area of reinforcement } \\
\text { (negative B.M) }\end{array}$ & $4213.6 \mathrm{~mm}^{2}$ & $3588 \mathrm{~mm}^{2}$ & $14.8 \%$ \\
\hline $\begin{array}{l}\text { Distribution Steel area } \\
\text { (positive B.M) }\end{array}$ & $1234.27 \mathrm{~mm}^{2}$ & $1126.08 \mathrm{~mm}^{2}$ & $8.8 \%$ \\
\hline $\begin{array}{l}\text { Distribution Steel area } \\
\text { (negative B.M) }\end{array}$ & $866.64 \mathrm{~mm}^{2}$ & $739.68 \mathrm{~mm}^{2}$ & $14.6 \%$ \\
\hline $\begin{array}{l}\text { Total Cost of Steel } \\
\text { ** }\end{array}$ & $322202 \mathrm{INR}$ & $284989 \mathrm{INR}^{2}$ & $\begin{array}{l}37213 \mathrm{INR} \\
(11.5 \%)\end{array}$ \\
\hline
\end{tabular}

** The cost of steel taken is Rs 32500/quintal as per rates in Indian market.

Table 1 shows the comparison of the two methods, conventional method in STAAD and FEM in ANSYS with respect to maximum bending moments, area of steel reinforcement required and the cost of steel. It can be seen clearly that there is significant reduction in moments and consequently cost of project is reduced by $11.5 \%$. The cost difference can be remarkable in large projects and effective design can be achieved through FEM.

\section{CONCLUSION}

The study results clearly infer that the culvert if designed through finite element method rather than conventional method would not only save the material and money but also make the design safer. Hence following points are concluded from the study

- Results show the difference of $16.46 \%$ in positive bending moment.

- A difference of $27.4 \%$ is seen in negative bending moment in FEM from conventional method

- Area of steel for maximum positive bending moment is decreased by $8.6 \%$ and for maximum negative bending moment it is decreased by $14.8 \%$

- Distribution steel is decreased by $8.8 \%$ for maximum positive bending and $14.6 \%$ for maximum negative moment.

- Difference in the cost is $11.5 \%$ which is huge for large projects.

- Modeling and design in ANSYS is easier than any other software and gives more economic design.

The application of FEM through ANSYS software can save large amount of money and effort in design and implementation of box culvert and other structures.

\section{REFERENCES}

[1] Patil, A.D, Galatage, A.A, Analysis of Box Culvert under Cushion Loading ,(2016), International Advanced Research Journal in Science, Engineering and Technology Vol. 3, Issue 6, p. 163-166.

[2] Vinod Kumar Y, Dr. Srinivas C, Analysis and Design of Box Culvert By Using Computational Method, (2015), International Journal of Engineering \& Science Research, Vol-5, Issue-7, p. 850-861.

[3] Lande A. C, Kamane S. K., Madhik S. A, Finite Element Analysis of Box Culvert, (2015), International Journal of Advanced Structures and Geotechnical Engineering, Vol 04, No.1, p. 57-62

[4] Chijiwa N., Zhu X., Ohno H., Tanabe S., Nakarai K., Maekawa K., Delayed Shear Crack Formation of Shallow RC Box Culverts in Service, (2015), Mechanics of Physics of Creep, Shrinkage and Durability of Concrete and Concrete Structures, Engineering Mechanics Institute @ASCE Vienna, Austria

[5] Kalyanshetti M. G, Gosavi S. A, Analysis of Box Culver- Cost Optimization For Different Aspect Ratios Of Cell, (2014), International Journal of Research in Engineering and Technology, Vol. 03, 04, p. 508-516

[6] Kolate N., Mathew M., Mali S., Analysis and Design of RCC Box Culvert, (2014), International Journal of Scientific \& Engineering Research, Vol.5, 12, p. 36-41

[7] Kattimani K. S, Shreedhar R, Parametric Studies Of Box Culvert, (2013), International Journal of Research in Engineering and Science, Vol. 1, 01, p. 58-65

[8] Shreedhar S, Shreedhar R, Design Coefficient for Single and Two Cell Box Culvert, (2013), International Journal of Civil and Structural Engineering, Vol. 3,03 p.475-494

[9] Chen S. S, Harik I. E, Dynamic Effect of a Moving Truck on a Culvert, (2012), JournalOf Bridge Engineering, Vol. 17, 02, p 123-129

[10] Kim K., Yoo C. H, Design Loading For Deeply Buried Box Culverts, IR-02-03, Highway Research Center, Auburn University, Alabama 
[11] Garg A. K, Abolmaali A., Finite Element Modeling and Analysis of Reinforcement Concrete Box Culverts, (2009) Journal Of Transportation Engineering@ ASCE,Vol. 135, 03, p. 121-128

[12] Abolmaali A, Garg A, Shear Behavior and Mode of Failure for ASTM C1433 Precast Box Culverts, (2008), Journal Of Bridge Engineering @ ASCE,Vol 13, 4, p 331-338

[13] Abolmaali A., Garg A. K., Effect of Wheel Load on Shear Behavior of Precast Reinforced Concrete Box Culverts, (2008), Journal of Bridge Engineering@ ASCE, Vol. 13, 01, p 93-99

[14] Design of Bridges fourth edition by Krishna Raju N. Oxford and IBH Publication

\section{AUTHOR PROFILE}

Saurav was born in Patna, India. He is presently working as Assistant Professor (II) in Jaypee University of Information Technology, Waknaghat, Solan, H.P. Soon after obtaining his Bachelor of Engineering degree with distinction in Civil Engineering from Birsa Institute of Technology Sindri, Gov. of Jharkhand in the year 2009, he worked in a construction industry for a year. He then qualified GATE exam and perused his M.Tech degree with specialization in Structural Engineering from IIT BHU in the year 2012. He has more than 5 four years of teaching experience both at UG and PG level. Along with teaching he is also pursuing Ph.D. (Thesis Submitted) from Jaypee University of Information Technology. He guided dozens of students at UG and PG levels. He has also technical papers published to his credits. He has passion for teaching and also helps students for preparing for the UPSC Engineering Services Examinations. He also helps students in learning different civil engineering software like ANSYS, STADD PRO, etc.

Ishaan Pandey was born in Lucknow, Uttar Pradesh, India. He has completed his M. Tech degree with specialization in Structural Engineering with distinction marks from Jaypee University of Information Technology, Waknaghat, Solan, Himachal Pradesh, India in 2017. He has got 1 year experience of teaching and sound knowledge of design and drafting software namely AutoCAD, STAADPro and ANSYS V14.5. Ishaan is a workaholic and kind person. He has also pertained knowledge of site execution and implementation of drawings. 